\title{
Spectrum of Pulsion Esophageal Diverticulum and Approach to the Management Based on Presence or Absence of Symptoms
}

\section{Ajeet Kumar Lohana*, Rajesh Bansari, Fakhar Ali Qazi Arisar, Wasim Jafri}

Department of Medicine, Section of Gastroenterology, Aga Khan University Hospital, Karachi, Pakistan

*Corresponding Author: Ajeet Kumar Lohana, MBBS, FCPS Gastroenterology, Department of Medicine, Section of Gastroenterology, Aga Khan University Hospital, Karachi, Pakistan.
Received: May 25, 2020

Published: June 19, 2020

(C) All rights are reserved by Ajeet Kumar

Lohana., et al.

\section{Abstract}

Introduction: Pulsion esophageal diverticulum (PED) is a rare esophageal disorder. A minority of individuals develops characteristic symptoms, such as dysphagia,; however; the majority does not produce any symptoms. Progression and requirement of a follow up in asymptomatic diverticulum is not well determined. In this study, the spectrum of presentation and approach to management of PED based on presence or absence of symptoms is determined.

Method: In this retrospective study, 28 consecutive patients identified having PED from January 2010 to December 2017 . Information regarding clinical spectrum of the disease and treatments were recorded. Patients follow up charts were reviewed to determine onset of new symptoms in asymptomatic individuals and resolution/recurrence of symptoms in symptomatic individuals after respective treatments.

Results: Mid esophageal diverticulum (MD) was the most common diverticulum (17/28) (60.7\%). 13/28 (46.42\%) of individuals were asymptomatic and all of these patients harbor MD of $\leq 1 \mathrm{~cm}$ in size. Over a mean follow up of 14 months none of asymptomatic patient developed new symptoms and/or complications. A total of 15/28 (53.54\%) patients were symptomatic, predominantly with dysphagia (10/15) (66.66\%) and having Zenker's Diverticulum (ZD) among 4, MD among 4, Epiphrenic Diverticulum (ED) among 6, and MD+ED among 1 patient. Out of 15 symptomatic patients, one third (5/15) of patients underwent surgical interventions due to persistent troublesome symptoms; another one third (5/15) could not undergo surgical resection despite persistent symptoms because of comorbid condition and patient refusal; and in remaining one third (5/15) of patients the symptoms were fairly controlled with supportive treatment only. $1 / 5(20 \%)$ of symptomatic individuals who underwent surgery had recurrence of symptoms postoperatively.

Conclusion: MD type with $\leq 1 \mathrm{~cm}$ may not require treatment or long term follow up. Zenker's and Epiphrenic Diverticula produce persistent symptoms even if small. Two thirds of such symptomatic patients require surgical or endoscopic resection because of troublesome symptoms; however rest of symptomatic patients can be controlled with supportive treatment without necessitating surgical intervention.

Clinical Significance: The study determines the effective approach to PED based on presence or absence of symptoms.

Keywords: Esophagus; Zenker's Diverticulum; Epiphrenic Diverticulum; Mid-esophageal Diverticulum; Pulsion; False Diverticulum; Treatment; Symptom Based Approach 


\section{Introduction}

Pulsion Esophageal Diverticulum (PED) is a false diverticulum which forms secondary to out pouching of mucosal $+/$ - sub mucosal layer from inside to outside of the esophageal lumen. In contrast to PED; the traction type esophageal diverticulum results secondary to out pouching of all layers of esophageal wall and often secondary to a pathological process- such as inflammation or tumors, which involve the lumen or outside the lumen of the esophagus [1]. PED develop secondary to imbalance of intraluminal pressure and mucosal wall tension, with absence of an associated mucosal disease. Gastrointestinal (GI) diverticula are commonly seen in large bowel; however, they are infrequently encountered in upper GI tract involving esophagus, duodenum, and other parts of small bowel. Pulsion Esophageal Diverticulum (PED) is also categorized based on the location of the diverticulum in esophagus. Zenker's diverticulum (ZD) and Killian-Jamieson diverticulum occurs below the cricopharyngeus muscle and just above the upper esophageal sphincter (UES) in posterior or antero-lateral wall of hypopharynx respectively. Mid-esophageal diverticulum (MD) occurs in the segment of esophagus starting below the UES and up to $10 \mathrm{~cm}$ proximal to gastro esophageal junction (GEJ) [2,3]; and lastly Epiphrenic diverticulum, which occurs just above the lower esophageal sphincter within $10 \mathrm{~cm}$ of GEJ $[4,5]$.

Majority of patients with pulsion esophageal diverticulum tend to remain asymptomatic [6-8]. Some patients develop symptoms originating from upper GI tract such as dysphagia, regurgitation, halitosis, and rarely bleeding; while a small number of individuals develop predominantly upper respiratory tract symptoms such as cough, choking, and aspiration [6].

A large number of individuals with PED do not seek a medical advice; receive a treatment; or follow up with the physicians because of their mild intermittent symptoms or completely asymptomatic disease course [7,9-11]. In certain situations however, surgical resection of the diverticulum is necessary due to rapid progression in the size of the diverticulum and/or development of life threatening complications such as aspiration pneumonia [12]. Figure 1 shows the different types of diverticulum diagnosed on endoscopy and radiological investigations.

Owing to the rarity of the disorder, lack of a standard guideline; the approach to the management of pulsion esophageal di-

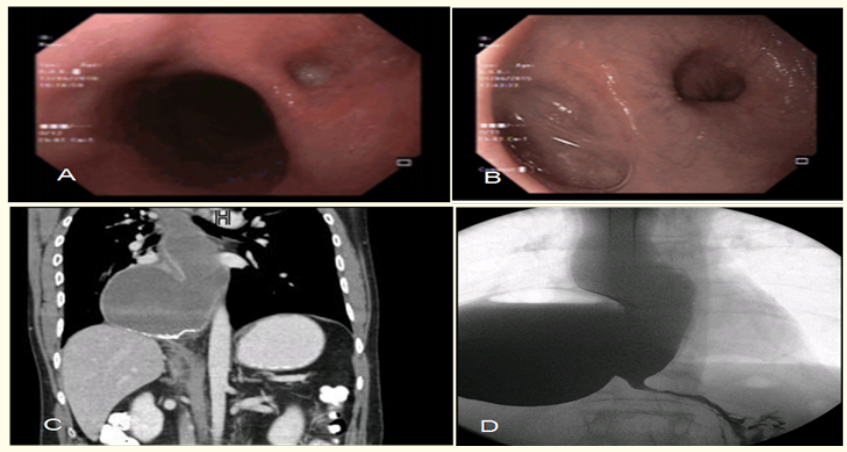

Figure 1: Types of pulsion esophageal diverticulum. Small Mid esophageal diverticulum Endoscopic view (A); A Large epiphrenic diverticulum Endoscopic view (B); A Large Epiphrenic diverticulum on CT scan coronal view (C); and Large Epiphrenic diverticulum on Barium swallow (D).

verticulum is largely individualized. Furthermore, the available literature supports different implications while managing patients with symptomatic pulsion esophageal diverticulum; however, implication in terms of management-resection vs. surveillance among patients with asymptomatic pulsion esophageal diverticulum is not well determined [6]. Therefore, in this retrospective observational review of patients, we intend to determine spectrum of presentation of pulsion esophageal diverticulum, as well as determine the approach to the management of patients among asymptomatic and symptomatic patients with pulsion esophageal diverticulum.

\section{Methods}

It was a retrospective observational study. The study was conducted in the Department of Medicine, Aga Khan University Hospital Karachi Pakistan. A total of 32 consecutive patients with suspected pulsion esophageal diverticulum were identified from January 2010 to December 2017. After reviewing their clinical, endoscopic and radiological profiles; 4 patients were excluded because of presence of traction type diverticulum-esophageal tuberculosis $(n=1)$ and malignant esophageal ulcer $(n=3)$.

Data from 28 patients with pulsion esophageal diverticulum including demographics; spectrum of symptoms; upper GI endoscopic findings i.e. size and site of diverticulum; radiological findings; frequency of surgical or endoscopic resection; surgical findings; 
and frequency of post-operative complications were determined. These 28 patients were grouped in to two based on presence or absence of diverticulum related symptoms in to symptomatic vs. asymptomatic individuals. The diverticulum related symptoms were dysphagia, chest pain, regurgitation and heart burn, halitosis, bleeding from diverticulum, cough, choking, and aspiration pneumonia. Patients follow up charts were reviewed in order to determine occurrence of symptoms and/or complications among asymptomatic individuals; while resolution, worsening or recurrence of symptoms among symptomatic individuals who received surgical or non-surgical treatments.

Continuous variables presented as means or median, categorical variable presented as frequencies or proportions. Differences among symptomatic vs. asymptomatic individuals were derived using test of correlations-chi-square test and independent student's t-test where appropriate. $\mathrm{P}$ value $\leq 0.05$ was considered significant.

\section{Results}

A total of 28 patients were found to have pulsion esophageal diverticulum which were encountered during study period (January 2010 to December 2017). Out of 28 patients, 4 patients had Zenker's Diverticulum (ZD), 17 patients had Mid-esophageal Diverticulum (MD), 6 patients had Epiphrenic Diverticulum (ED), and 1 patient had combined MD and ED. Baseline characteristics of 28 patients according to type of pulsion esophageal diverticulum are presented in table1.

Mean age was higher among patients with ED than of those with ZD and MD i.e. 67, 63.5, 54.4 years respectively. Out of 28 subjects, $15(53.5 \%)$ subjects were males. A total of 15 (53.7\%) subjects were symptomatic with variables symptoms, predominantly dysphagia and others, as shown in table1.

Table1: Characteristics of Individuals with all types of pulsion esophageal diverticulum

\begin{tabular}{|c|c|c|c|c|c|c|}
\hline \multicolumn{2}{|c|}{ Variables } & \multicolumn{4}{|c|}{ Pulsion Esophageal Diverticulum $(\mathrm{N}=28)$} & \multirow[b]{2}{*}{$\begin{array}{l}\text { Total } \\
\text { N (\%) }\end{array}$} \\
\hline & & $\begin{array}{c}Z^{1} \\
(n=4)\end{array}$ & $\begin{array}{c}\mathrm{MD}^{2} \\
(\mathrm{n}=17)\end{array}$ & $\begin{array}{c}E^{3} \\
(n=6)\end{array}$ & $\begin{array}{l}\text { MD+ED } \\
(n=1)\end{array}$ & \\
\hline Gender & $\begin{array}{l}\text { Males } \\
\text { Females }\end{array}$ & $\begin{array}{l}1 \\
3\end{array}$ & $\begin{array}{c}10 \\
7\end{array}$ & $\begin{array}{l}4 \\
2\end{array}$ & - & $\begin{array}{l}15(53.57 \%) \\
13(46.42 \%)\end{array}$ \\
\hline Symptomatic & & 4 & 4 & 6 & 1 & $15(53.57 \%)$ \\
\hline $\begin{array}{l}\text { Mean Duration of Symptoms before } \\
\text { diagnosis (months) }\end{array}$ & & 27.25 & 22.55 & 43.02 & 180 & \\
\hline Hospital Service Encounter & Gastroenterologist & 1 & 17 & 4 & - & $22(78.5 \%)$ \\
\hline \multirow[t]{3}{*}{ Size of Diverticulum } & Small $(\leq 1 \mathrm{~cm})$ & 3 & 16 & - & 1 & $20(71.4 \%)$ \\
\hline & Medium $(2-4 \mathrm{~cm})$ & - & 1 & 4 & - & $5(17.8 \%)$ \\
\hline & Large $(\geq 5 \mathrm{~cm})$ & 1 & 0 & 2 & - & $3(10.7 \%)$ \\
\hline \multirow[t]{2}{*}{ Mode of Diagnosis* } & Endoscopic & 1 & 17 & 5 & 1 & $24(85.7 \%)$ \\
\hline & Radiological & 3 & - & 1 & - & $4(14.3)$ \\
\hline \multirow{2}{*}{$\begin{array}{l}\text { Symptoms break out in symptomatic } \\
\text { individuals }(n=15)\end{array}$} & Dysphagia & 4 & 1 & 5 & - & $10(35.7 \%)$ \\
\hline & Heart burn & -- & 2 & & 1 & $3(10.7 \%)$ \\
\hline
\end{tabular}

Citation: Ajeet Kumar Lohana., et al. "Spectrum of Pulsion Esophageal Diverticulum and Approach to the Management Based on Presence or Absence of Symptoms". Acta Scientific Gastrointestinal Disorders 3.7 (2020): 02-08. 


\begin{tabular}{|c|c|c|c|c|c|c|}
\hline \multirow{3}{*}{$\begin{array}{l}\text { Indication of endoscopy in } \\
\text { asymptomatic individuals }(n=13)\end{array}$} & Dyspepsia & & 8 & \multirow{2}{*}{\multicolumn{2}{|c|}{$\begin{array}{c}2(7.14 \%) \\
2(7.14 \%) \\
1(3.5 \%)\end{array}$}} & $8(28.5 \%)$ \\
\hline & $\begin{array}{l}\text { Screening (bleeding risk } \\
\text { stratification) }\end{array}$ & & 2 & & & \\
\hline & $\begin{array}{l}\text { Weight loss (Non Hodgkin } \\
\text { lymphoma) }\end{array}$ & & 1 & & & \\
\hline
\end{tabular}

${ }^{1}$ :ZD-Zenker's Diverticulum, ${ }^{2}$ : MD-Mid Esophageal Diverticulum, ${ }^{3}$ : ED-Epiphrenic Diverticulum. *: Endoscopic diagnosis was made with direct visualization of diverticular sac with no adjacent inflammation or evidence of malignancy. ${ }^{+}$: Motility disorders were detected using high resolution esophageal manometry (HRM); and it was tested only among symptomatic individuals. 2 patients had non-specific hyper motility disorder and 1 has achalasia.

Baseline characteristics of asymptomatic patients 13 (46.42\%) (table1) plus their difference to symptomatic diverticular patients are determined in table 2 . All 13 individuals with asymptomatic disease harbor Mid-esophageal diverticulum of small size i.e. $\leq 1$ $\mathrm{cm}$ in diameter. These patients were followed for a mean duration of 14 months and none of them reported onset of new symptoms.
Patients with comparatively higher age, Zenker's or Epiphrenic type of pulsion diverticulum, and diameter of 2 to $5 \mathrm{~cm}$ or above tend to be symptomatic as shown in table 2 .

Out of 15 symptomatic patients, a total of 5 underwent surgical intervention and 10 patients were initially managed with sup-

\begin{tabular}{|c|c|c|c|c|c|c|}
\hline \multirow{2}{*}{\multicolumn{2}{|c|}{ Variables }} & \multicolumn{2}{|c|}{ Asymptomatic (n=13) } & \multicolumn{2}{|c|}{ Symptomatic $(n=15)$} & \multirow[b]{2}{*}{$\mathbf{P}^{*}$ value* } \\
\hline & & Mean & Frequency (\%) & Mean & Frequency (\%) & \\
\hline \multicolumn{2}{|l|}{ Age (years) } & 53.92 & & 63.80 & & 0.031 \\
\hline \multirow[t]{2}{*}{ Gender } & Males & & $9(32.1 \%)$ & & $6(21.4 \%)$ & \multirow{2}{*}{0.151} \\
\hline & Females & & $4(14.2 \%)$ & & $9(32 \%)$ & \\
\hline \multicolumn{2}{|c|}{ Symptoms duration before diagnosis (months) } & 24.18 & & 41.29 & & 0.336 \\
\hline \multicolumn{2}{|c|}{ Follow up Duration (months) } & 14 & & 10 & & 0.533 \\
\hline \multirow[t]{4}{*}{ Diverticulum type } & ZD & & 0 & & $4(100 \%)$ & 0.048 \\
\hline & MD & & $13(76.4 \%)$ & & $4(23.54 \%)$ & 0.0003 \\
\hline & ED & & 0 & & $6(100 \%)$ & 0.005 \\
\hline & $\mathrm{MD}+\mathrm{ED}$ & & 0 & & $1(100 \%)$ & na \\
\hline \multirow[t]{3}{*}{ Size of Diverticulum } & Small $(\leq 1 \mathrm{~cm})$ & & $13(65 \%)$ & & $7(35 \%)$ & 0.002 \\
\hline & Medium $(2-4 \mathrm{~cm})$ & & 0 & & $5(100 \%)$ & 0.044 \\
\hline & Large $(\geq 5 \mathrm{~cm})$ & & 0 & & $3(100 \%)$ & 0.226 \\
\hline Motility Disorder & & & 0 & & $3(100 \%)$ & na \\
\hline $\begin{array}{l}\text { Intervention }(\mathrm{n}=15) \\
\text { Surgical } \\
\text { Non-surgical }\end{array}$ & & & $\begin{array}{l}0 \\
0\end{array}$ & & $\begin{array}{l}5(33.3 \%) \\
10(66.6 \%)\end{array}$ & na \\
\hline $\begin{array}{l}\text { New symptom onset and/or complica- } \\
\text { tion in asymptomatic patients }{ }^{+}(n=13)\end{array}$ & & & $0 / 13(0 \%)$ & & - & na \\
\hline
\end{tabular}


Failure to control or recurrence of symptoms in symptomatic patients ${ }^{+}(n=15)$

Surgical

Non-surgical

Table2: Difference in between variables among symptomatic vs. asymptomatic pulsion esophageal diverticulum ${ }^{*}$ p-value were derived using correlation tests; chi square and independent t-test where appropriate; na- not applicable. ${ }^{+}$onset of new symptoms was applicable in case of previous asymptomatic disease; while recurrence of symptoms or failure to control symptoms was applicable to symptomatic individuals only, who had prior documented symptoms

portive treatment including acid suppression using proton pump inhibitors for reducing heartburn and regurgitation. 5 out of 15 $(33.3 \%)$ symptomatic patients underwent surgical excision of the diverticulum owing to disabling symptoms, as shown in table 3 . Only 1 out of 5 had recurrence of symptoms post surgically. The group of symptomatic patients who received non-surgical therapy $(\mathrm{n}=10) ; 5$ patients had persistent symptoms despite continuous medical therapy, however; they did not undergo surgical resection because of limitations; and remaining 5 patients had reasonable control of their symptoms with medications.

\begin{tabular}{|c|c|c|c|c|c|c|}
\hline Type of Diverticulum & $\begin{array}{l}\text { Mode of } \\
\text { diagnosis }\end{array}$ & $\begin{array}{l}\text { Predominant } \\
\text { symptoms }\end{array}$ & Surgical intervention & \begin{tabular}{|c|} 
Duration of Post \\
operative \\
Hospital stay
\end{tabular} & Complication & $\begin{array}{l}\text { Recurrence of } \\
\text { symptoms }\end{array}$ \\
\hline 1. Zenker's diverticulum & Radiological & Dysphagia & $\begin{array}{l}\text { Zenker's Diverticulectomy; } \\
\text { left neck incision }\end{array}$ & 1 & None & None \\
\hline 2. Zenker's diverticulum & Radiological & $\begin{array}{l}\text { Choking/ } \\
\text { cough }\end{array}$ & \begin{tabular}{|c|}
$\begin{array}{c}\text { Zenker'sDiverticulecopexy; } \\
\text { endoscopic stapling }\end{array}$ \\
\end{tabular} & 1 & None & None \\
\hline 4. Epiphrenic diverticulum & Endoscopic & Dysphagia & Lateral thoracotomy & 4 & None & None \\
\hline 5. Epiphrenic diverticulum & Radiological & Dysphagia & $\begin{array}{l}\text { Laparotomy with abdomi- } \\
\text { nal approach }\end{array}$ & 4 & None & Yes \\
\hline
\end{tabular}

Table 3: Details of patients who underwent surgical interventions

The limitations for surgical resection among five subjects (ZD $=1, \mathrm{ED}=3, \mathrm{MD}+\mathrm{ED}=1$ ) with persistent symptoms were cardiopulmonary morbidity $(n=2)$, refusal by patient $(n=2)$ and technically difficult position of Zenker's diverticulum $(n=1)$.

\section{Discussion}

In concordance with previous published literature, nearly half $13 / 28(46.42 \%)$ of our patients in this cohort were asymptomatic [7,9-11]. These asymptomatic individuals were encountered with health facilities secondary to the reasons unrelated to the presence of pulsion esophageal diverticulum as described in table1. Additionally, these patients remained asymptomatic when they were followed for occurrence of new symptoms and/ or complication over mean duration of 14 months. Mid-esophageal type and small diverticular size of $\leq 1 \mathrm{~cm}$ remain asymptomatic, in comparison to ZD and ED, which tend to cause symptoms even if small. In one large case series of patients with pulsion esophageal diverticulum described that nearly $80 \%$ patients with diverticulum have milder symptoms and do not warrant treatment [6-8]. However, in other studies the frequency of asymptomatic individuals tends to be less than $50 \%[11,13]$. When those asymptomatic patients were followed over a variable period of time, very few reported onset of new symptoms or development of a complication [7,8,11,13].

In one study, the diverticular enlargement was seen in only $16 \%$ of patients who initially report milder symptoms over a period of 12 years [8]. A systematic review was conducted in 2001 over sub- 
jects with pulsion esophageal diverticulum reported that, 83 out of $133(62 \%)$ of patients who possess diverticula with mild or absent symptoms report no progression of disease and only less than $10 \%$ report development of a new symptoms and/or a complication [6]. Despite studies which did not report progression of diverticulum among fairly asymptomatic patients; some researchers claim early surgical evaluation in all patients with pulsion esophageal diverticulum due to risk of development of life-threatening complications [12]. This observation was based on an experience of 20 patients, out of those 3 developed aspiration pneumonia while one patient died because of it.

Nonetheless, considering the perioperative risks related to surgical resection of the diverticulum, including post-operative leaks, nosocomial infection, and cost; there are studies which support surgical intervention only among symptomatic individuals $[8,12]$.

In our study, 5 (33\%) patients-3 with ZD and 2 with ED who had very disabling symptoms ended up doing surgical resection (table3). All three who underwent Zenker's diverticulectomy had rapid resolution of their symptoms, however; out of two who underwent Epiphrenic diverticulectomy, one patient reported persistent symptoms of dysphagia even after 2 years of follow up. None of our patients have been evaluated for endoscopic resection of symptomatic diverticulum because of unavailability of expertise at that time.

With the recent advent of newer mini invasive surgery (MIS), such as laparoscopic staple diverticulectomy with or without myotomy, Video-assisted thoracoscopic surgery (VATS), and flexible endoscopic diverticulopexy; surgical management of functional esophageal diverticula has been revolutionized $[14,15]$. In one recent study of mini invasive surgeries over 57 subjects with predominant thoracic (epiphrenic) type diverticulum among symptomatic patients, resulted in improvement in median dysphagia score from 3 to $1(\mathrm{P}<0.001)$, and improvement in median Gastro-esophageal Reflux Disease-Health-Related Quality of Life score after surgery [14]. Furthermore, their preferred surgical approach was VATS among 39 (68\%) followed by laparoscopic approach among 18 (32\%) patients, and conversion to open surgical approach among only $3(5.2 \%)$ patients. There was $0 / 57(0 \%) 30$-day mortality, and overall 1/57 (1.75\%) in hospital mortality. The overall morbidity was 17/57 (30\%) . There were 4/57 (7\%) patients who reported post-surgical leaks that required re-operation. The common sur- gical technique used was diverticulectomy + myotomy 47 (82\%), while among 20 (35\%) fundoplication was also added. This study established a robust evidence of employing Mini Invasive Surgery (MIS) to help improve surgical outcomes, decreasing morbidity and mortality. For asymptomatic individuals, however; author claim to follow such patients and intervene early if individuals report new symptoms or develop any complications.

The feasibility and improved post-surgical outcomes after advent of mini invasive techniques for the management of pulsion esophageal diverticulum has largely replaced the traditional modes of open surgical resection, and are now appear to be the standard of care $[10,15-20]$.

Frequency of esophageal motility disorder among our cohort of patients was low i.e. 3/15 (20\%) in symptomatic group of patients.2 patients had Nonspecific hyper-motility disorder and one had achalasia. Esophageal manometry was not available in asymptomatic individuals. Several studies report a significant proportion of individuals with pulsion esophageal diverticulum possess an underlying esophageal motility disorders $[6,14,18,21]$. The commonest esophageal motility disorder identified among subjects with PED is a non-specific esophageal motility disorder followed by achalasia, diffuse esophageal spasm and hypertensive esophageal motility disorders in that order [6,14]. In presence of underlying motility disorders, surgeon prefers to perform myotomy in order to prevent diverticulum recurrence, and also to minimize the risk of post-operative leaks $[6,14]$.

\section{Conclusion}

Our study demonstrates that that Mid-esophageal Diverticulum with $\leq 1 \mathrm{~cm}$ does not require treatment or long term follow up. Zenker's and Epiphrenic Diverticula produce persistent symptoms even if small. Two thirds of symptomatic patients require surgical resection because of troublesome symptoms; however rest of the symptomatic patients can be controlled with supportive treatment without necessitating surgical intervention.

Open surgical resection of diverticulum seem to be an effective option for treatment of large and/or symptomatic diverticulum in our cohort of patients with rapid resolution of symptoms and no perioperative morbidity or mortality. However, given newer surgical options; a careful selection of patients is required before opting for open surgical resection of the diverticulum. 


\section{Clinical Significance}

This study determines the spectrum of presentation of pulsion esophageal diverticulum. This study also determines a rational approach to the management of pulsion esophageal diverticulum based on presence or absence of diverticulum related symptoms.

\section{Bibliography}

1. Yam J AS. Esophageal Diverticula. StatPearls [Internet]: Treasure Island (FL): StatPearls Publishing; 2019 Jan-; [Updated 2019 Feb 15].

2. Baker ME., et al. "Esophageal diverticula: patient assessment". Seminars in Thoracic and Cardiovascular Surgery 11.4 (1999): 326-336.

3. Burton R., et al. "Spontaneous rupture of an oesophageal diverticulum". Medical Journal of Australia 2.25 (1971): 1289.

4. Testoni PA., et al. "MRCP-secretin test-guided management of idiopathic recurrent pancreatitis: long-term outcomes". Gastrointestinal Endoscopy 67.7 (2008): 1028-1034.

5. Orringer MB. "Epiphrenic diverticula: fact and fable". The Annals of Thoracic Surgery 55.5 (1993): 1067-1068.

6. Thomas M., et al. "Oesophageal diverticula". British Journal of Surgery 88.5 (2001): 629-642.

7. Habein Hc., et al. "Diverticula of the lower part of the esophagus: a clinical study of one hundred forty-nine nonsurgical cases". Archives of Internal Medicine 97.6 (1956): 768-777.

8. Bruggeman LL and Seaman WB. "Epiphrenic diverticula. An analysis of 80 cases". The American Journal of Roentgenology Radium Therapy and Nuclear Medicine 119.2 (1973): 266-276.

9. Debas H., et al. "Physiopathology of lower esophageal diverticulum and its implications for treatment". Surgery, Gynecology and Obstetrics 151.5 (1980): 593-600.

10. Benacci JC., et al. "Epiphrenic diverticulum: results of surgical treatment". The Annals of Thoracic Surgery 55.5 (1993): 11091114.

11. Castrucci G., et al. "Tailored surgery for esophageal body diverticula". European Journal of Cardio-Thoracic Surgery 14.4 (1998): 380-387.
12. Altorki N., et al. "Thoracic esophageal diverticula. Why is operation necessary?" The Journal of Thoracic and Cardiovascular Surgery 105.2 (1993): 260-264.

13. Jordan J., et al. "New look at epiphrenic diverticula". World Journal of Surgery 23.2 (1999): 147-152.

14. Macke RA., et al. "Thoracic esophageal diverticula: a 15-year experience of minimally invasive surgical management". The Annals of Thoracic Surgery 100.5 (2015): 1795-1802.

15. Varghese Jr TK., et al. "Surgical treatment of epiphrenic diverticula: a 30-year experience". The Annals of Thoracic Surgery 84.6 (2007): 1801-1809.

16. Belsey R. "Functional disease of the esophagus". The Journal of Thoracic and Cardiovascular Surgery 52.2 (1966): 164.

17. Nehra D., et al. "Physiologic basis for the treatment of epiphrenic diverticulum". Annals of Surgery 235.3 (2002): 346.

18. D'journo X., et al. "Lower oesophageal sphincter dysfunction is part of the functional abnormality in epiphrenic diverticulum". British Journal of Surgery 96.8 (2009): 892-900.

19. Reznik S., et al. "Assessment of a pathophysiology-directed treatment for symptomatic epiphrenic diverticulum". Diseases of the Esophagus 20.4 (2007): 320-327.

20. Fekete F, Vonns C. Surgical management of esophageal thoracic diverticula. Hepatogastroenterology. 39.2 (1992): 97-99.

21. Streitz JM., et al. "Selective use of myotomy for treatment of epiphrenic diverticula: manometric and clinical analysis". The Archives of Surgery 127.5 (1992): 585-588.

\section{Assets from publication with us}

- Prompt Acknowledgement after receiving the article

- Thorough Double blinded peer review

- Rapid Publication

- Issue of Publication Certificate

- High visibility of your Published work

Website: www.actascientific.com

Submit Article: www.actascientific.com/submission.php

Email us: editor@actascientific.com

Contact us: +919182824667 